\title{
Percepção discente sobre cursos de graduação em Ciências Agrárias e Humanidades da UNESP'
}

\author{
Monique Matsuda dos Santos² \\ ORCID: 0000-0002-2694-3475 \\ Isabela Gomes Ferreira Pedroso ${ }^{2}$ \\ ORCID: 0000-0003-4326-5159 \\ Sandra Cristina de Oliveira ${ }^{2}$ \\ ORCID: 0000-0002-0968-0108
}

\section{Resumo}

No cenário das Instituições de Ensino Superior brasileiras, as justificativas para evasão ou permanência discente variam de acordo com a instituição e os cursos, dadas as suas peculiaridades, bem como as de seus estudantes. Entretanto, ainda são escassos os estudos e ações governamentais acerca da evasão escolar, o que mostra a falta de inovação acerca desse tema. Assim, o objetivo geral do presente trabalho consiste em avaliar a percepção de egressos e evadidos acerca dos cursos de graduação das áreas de Ciências Agrárias e de Humanidades dos Campi Experimentais da UNESP. Especificamente, pretende-se evidenciar um procedimento metodológico que possa identificar quais elementos pontuais têm influenciado na tomada de decisão dos discentes de evadirem ou de permanecerem nos referidos cursos. Para tanto, foi feito um levantamento (survey), por meio de questionário estruturado com 40 sentenças de múltipla escolha, que foi aplicado por e-mail e pelas redes sociais a uma amostra probabilística composta por 243 respondentes. Por fim, a técnica multivariada de análise de clusters associada a testes de hipóteses não paramétricos foi utilizada para verificar a existência de diferença entre as percepções de egressos e evadidos que indicasse influência em sua decisão. Os resultados mostraram que, de maneira geral, egressos e evadidos apresentam percepções positivas quanto ao curso escolhido, bem como com respeito às condições de infraestrutura geral dos campi. Para dois cursos, um em cada área, foram observadas diferenças significativas entre as percepções de egressos e evadidos, sendo que principalmente características intrínsecas relacionadas aos discentes e ao seu bem-estar, tais como, identificação com o curso; motivação ou persistência para concretizar os objetivos; saúde e estabilidade pessoal e/

1- Agradecimento ao CNPq (Conselho Nacional de Desenvolvimento Científico e Tecnológico) pelo auxílio financeiro à pesquisa e pelas bolsas de iniciação científica (Edital CNPq 22/2014 - Ciências Humanas, Sociais e Sociais Aplicadas - Processos 471389/2014-5, 42685/2017 e 42697/2017, respectivamente).

2- Universidade Estadual Paulista (UNESP), Tupã-SP, Brasil. Contatos: niquematsuda@gmail.com; pedrosoisabela15@gmail.com; sandra. oliveira@unesp.br 
ou familiar; e integração socioacadêmica com outros discentes foram as que interferiram direta ou indiretamente na tomada de decisão.

\section{Palavras-chave}

Evasão escolar - Permanência estudantil - Ensino Superior - UNESP.

\section{Student perception of the Agricultural Sciences and Humanities undergraduate courses at São Paulo State University (UNESP), Brazil*}

\section{Abstract}

In the scenario of Brazilian Higher Education Institutions, the justifications for dropout or permanence of students vary according to the school and its courses, given their peculiarities, as well as those of their students. However, studies and governmental actions on school dropout are still scarce, which shows the lack of innovation on this topic. Thus, the general objective of the present work is to evaluate the perception of graduates and student dropouts in relation to their undergraduate courses in the areas of Agricultural Sciences and Humanities, from the Experimental Campi of the São Paulo State University (UNESP), Brazil. Specifically, it is intended to show a methodological procedure that can identify which specific elements have influenced the students' decision to evade or to stay in the referred courses. Thus, a survey was carried out through a structured questionnaire with 40 multiple choice sentences, which was applied by email and through social networks to a probabilistic sample of 243 respondents. Finally, the multivariate clustering analysis associated with testing nonparametric hypotheses was used to verify the existence of a difference between the perceptions of graduates and dropouts that indicated influence on their decision. The results showed that, in general, graduates and dropouts have positive perceptions regarding the chosen course, as well as with respect to the general infrastructure conditions of the campi. For two courses, one in each area, significant differences were observed between the perceptions of graduates and dropouts, with mainly intrinsic characteristics related to students and their wellbeing, such as identification with the course; motivation and persistence to achieve the objectives; personal and / or family health and stability; and socio-academic integration with other students were those that directly or indirectly interfered in decision-making.

\section{Keywords}

School dropout - Student residence - Higher education - Brazilian universities. 


\section{Introdução}

No cenário das Instituições de Ensino Superior (IES) brasileiras, as justifıcativas para evasão ou permanência discente, apontadas em diversos estudos, variam de acordo com a instituição e os cursos pesquisados, dadas as suas peculiaridades, bem como as de seus estudantes (SILVA, 2013).

Apesar de ser do discente a decisão de evadir ou não de um curso, entende-se que a forma como a IES se estrutura para o oferecimento de cursos de graduação e as condições proporcionadas para a manutenção do discente podem ser determinantes nessa decisão. Há ainda uma resposta do mercado de trabalho de aceitação dos egressos, que também pode influenciar na opção do estudante de permanecer no curso no qual ingressou. Assim, tem-se a clareza de que a decisão do discente está permeada por fatores advindos de contextos diversos.

Uma avaliação da evasão discente deve ser baseada em estudos que proporcionem conhecimento e informações sobre o assunto, de forma a contribuir na elaboração de estratégias para o seu controle. Entretanto, ainda são escassos os estudos e ações governamentais sobre evasão escolar, o que mostra a falta de inovação acerca desse tema.

Assim, o objetivo geral deste trabalho é avaliar a percepção de egressos e evadidos acerca dos cursos das áreas de Ciências Agrárias e de Humanidades dos Campi Experimentais da Universidade Estadual Paulista “Júlio de Mesquita Filho" (UNESP). Especificamente, pretende-se evidenciar um procedimento metodológico que possa identificar quais elementos pontuais têm influenciado na tomada de decisão dos discentes de evadirem ou de permanecerem nos referidos cursos, a fim de subsidiar órgãos gestores à aplicação de políticas públicas para combate à evasão na universidade.

A UNESP é uma das três universidades públicas mantidas pelo Governo do Estado de São Paulo, juntamente com a Universidade de São Paulo (USP) e a Universidade Estadual de Campinas (UNICAMP), e se destaca no ensino, na pesquisa e na extensão de serviços à comunidade. Foi fundada em 1976 e atualmente conta com 24 unidades, sendo 22 no interior, uma na capital e uma no litoral paulista, que ofertam conjuntamente 183 diferentes cursos de graduação em 60 carreiras de nível superior (MASSINI-CAGLIARI et al., 2018).

Sete dessas unidades, fixadas em municípios do interior paulista (Dracena, Itapeva, Ourinhos, Registro, Rosana, Sorocaba e Tupã), iniciaram suas atividades acadêmicas com oito cursos inéditos no segundo semestre de 2003, por meio de um Plano de Expansão da UNESP, e foram intituladas "Campi Experimentais" (CE).

Os CE da UNESP vêm passando por um processo de consolidação visando a se tornarem unidades universitárias, ou seja, com a mesma estrutura acadêmica e administrativa das demais. Em 2015, três CE se tornaram unidades universitárias: CE de Dracena; CE de Sorocaba; e CE de Tupã, agora intitulados, respectivamente, Faculdade de Ciências Agrárias e Tecnológicas (FCAT); Instituto de Ciência e Tecnologia (ICT); e Faculdade de Ciências e Engenharia (FCE).

Nesse processo, a maturidade e a qualidade do ensino são requisitos a serem alcançados, e a evasão discente deve ser avaliada e solucionada constantemente, a partir da identificação, mensuração e compreensão das suas causas. 


\section{Revisão bibliográfica}

\section{A evasão discente no ensino superior}

Segundo Silva Filho et al. (2007), a evasão discente é um dos problemas que mais afligem as IES, sendo que a busca de suas causas é objeto de diversos estudos nacionais e internacionais, pois implica o resultado dos sistemas educacionais. Se na esfera privada a evasão diminui o faturamento das IES, na esfera pública é encarada como perda do bem público. Mas, em ambos os casos, a evasão discente gera ociosidade de docentes, funcionários, equipamentos e espaço físico, ou seja, desperdícios acadêmicos, sociais e econômicos.

Tinto (1975) propõe um modelo teórico denominado Teoria da Integração do Estudante (TIE) para análise da permanência ou evasão discente no ensino superior. Posteriormente, Tinto (1993) aponta quatro fatores que podem influenciar na decisão do estudante de evadir ou de permanecer no ensino superior: atributos prévios ao seu ingresso na IES; relação entre objetivos e compromissos dos discentes e da instituição; relações formais e informais estabelecidas no ambiente acadêmico e social; e integração acadêmica e social proporcionada pelos fatores anteriores.

Desde então, alguns trabalhos tratam das causas da evasão discente no ensino superior considerando instituições e/ou cursos, sem avaliar o tipo de influência sobre a decisão pessoal do discente de evadir (MAINARDES et al., 2010; DIOGO et al., 2016). Outros estudos avaliam o perfil do evadido relacionando-o com os motivos declarados por ele para a desistência do curso (BARDAGI; HUTZ, 2009; POLYDORO et al., 2005). Já alguns autores defendem que a adoção de estratégias para redução da evasão discente deve estar diretamente relacionada à adoção de políticas para retenção (SILVA, 2013; TAMIN, 2013; TONTINI; WALTER, 2014).

Nesse sentido, é importante que sejam consideradas comparativamente a visão dos estudantes que evadem e daqueles que decidem permanecer na universidade e/ou concluem o curso (egresso), uma vez que características particulares podem os distinguir, bem como as condições oferecidas pelas IES para suprir as suas necessidades e garantir a sua permanência. Além disso, a avaliação de um curso pelo egresso é fundamental, pois ele vivencia a realidade do mercado de trabalho e pode apontar o que contribuiu positiva ou negativamente para sua vida e carreira profissional (NERES, 2015). Almeida (2018) reforça ainda que pesquisas com egressos são essenciais para o planejamento, definição e realimentação das políticas educacionais de uma instituição.

Cunha e Carrilho (2005) trazem para a discussão uma perspectiva psicossocial para a evasão, que consideram atrelada à dificuldade de adaptação e ao rendimento acadêmico, podendo ser afetados pelas vivências do discente durante o ano de ingresso no curso superior. Teixeira e Castro (2015) inserem no debate os stakeholders ${ }^{3}$ das IES, que são compostos por diversos atores que vão dos próprios discentes e candidatos ao ingresso, seus familiares, os docentes, a mídia, as instituições de fomento, a sociedade do entorno e o mercado de trabalho.

Baggi e Lopes (2011) apontam também a ausência de recursos financeiros como um dos principais fatores para a evasão discente no ensino superior. No entanto, salientam que a evasão não pode ser analisada sem levar em conta um contexto histórico mais vasto,

3- Stakeholders são públicos que estão direta ou indiretamente ligados a uma organização e têm interferência sobre ela. 
pois consideram que a realidade vivenciada em níveis anteriores de ensino reflete na forma de abandono de um curso superior. Além da formação escolar anterior deficitária, Santos (2014) destaca ainda que a falta de motivação para permanecer estudando, a dificuldade de organizar o tempo disponível para os estudos e/ou de conciliar estudo e trabalho estão entre os principais motivos que levam à evasão discente.

De forma complementar, Silva (2013) ressalta que as principais justificativas de evasão nas IES brasileiras apontadas em diferentes estudos são: a falta de perspectiva na carreira; o baixo nível de comprometimento com o curso, de participação em atividades acadêmicas e de desempenho escolar; a falta de apoio familiar; e as instalações precárias das IES.

No que diz respeito às ações de combate à evasão escolar, Baggi e Lopes (2011) afirmam que deve haver o acompanhamento e a implementação de políticas públicas educacionais em relação à igualdade de oportunidades de acesso à educação, e que a avaliação institucional, por ocorrer dentro da IES, com a comunidade acadêmica, no trabalho docente, na gestão das instituições e na definição curricular, é um importante meio de correção de metas e objetivos, podendo florescer métodos institucionais que garantam a permanência do discente.

Furtado e Alves (2012) consideram que as atividades de orientação profissional e de criação de eventos aos alunos, para resgatar aqueles com deficiência na formação do ensino médio, são possíveis instrumentos a serem implementados pelas universidades no combate à evasão discente. Nesse sentido, Bardagi e Hutz (2009) relatam que o envolvimento em atividades curriculares e/ou extracurriculares tem um impacto positivo no comprometimento e satisfação com o curso, promovendo a integração com o ambiente universitário e a redução da evasão.

Existem ainda as políticas de assistência estudantil, que têm o objetivo de direcionar recursos e mecanismos que possibilitem a permanência dos discentes em seus cursos, para que possam concluí-los de maneira satisfatória. Essas políticas devem estar voltadas às questões de ordem econômica (auxílio financeiro) e de ordem pedagógica e psicológica, contribuindo para a redução dos efeitos das desigualdades sociais e desestimulando a evasão discente (IMPERATORI, 2017).

Um exemplo de política de permanência estudantil é o Plano Nacional de Assistência Estudantil (PNAES), que foi criado em 2007 com o intuito de auxiliar discentes de baixa renda matriculados em cursos de graduação presencial em instituições federais de ensino superior. As ações do PNAES envolvem auxílio transporte, moradia estudantil, alimentação, inclusão digital, apoio pedagógico, assistência à saúde, dentre outras.

Outros exemplos são o Fundo de Financiamento do Ensino Superior (FIES) e o Programa Universidade para Todos (PROUNI), criados em 1999 e 2004, respectivamente. 0 primeiro financia cursos de graduação em IES privadas para estudantes que não têm condições de arcar com o custo das mensalidades de seus cursos; e o segundo proporciona bolsas de estudo parciais e integrais para cursos de graduação em IES também privadas. A seleção dos bolsistas utiliza como base a nota do Exame Nacional de Ensino Médio (ENEM).

Por fim, pode-se ressaltar os programas de apoio à permanência estudantil da USP, UNESP e UNICAMP, no estado de São Paulo, que atribuem auxílios e desenvolvem ações de apoio aos estudantes em situação de vulnerabilidade socioeconômica, buscando melhorar a condição de vida universitária e oportunizar a permanência desses discentes na universidade. 


\section{Metodologia}

Trata-se de uma pesquisa descritiva, quanto aos objetivos, com abordagem quantitativa, cuja unidade de análise são egressos e evadidos dos cursos de graduação das áreas de Ciências Agrárias (Zootecnia da FCAT/Dracena e Engenharia Agronômica do CE/Registro) e de Humanidades (Geografia do CE/Ourinhos, Turismo do CE/Rosana e Administração da FCE/Tupã) da UNESP, matriculados nos períodos letivos de 2003 a 2013.

Ainda que tenham se tornado unidades universitárias em 2015, os Campi de Dracena e de Tupã são tratados aqui como CE, uma vez que este trabalho se baseia em dados referentes aos discentes matriculados nesses cursos em anos letivos anteriores a 2015. Considera-se ainda o conceito de evasão estabelecido pela Comissão Especial de Estudos sobre a Evasão nas Universidades Públicas Brasileiras (ANDIFES/ABRUEM/SESu/MEC, 1997, p. 15), ou seja, é "a saída definitiva do aluno de seu curso de origem, sem concluí-lo".

Para alcançar os objetivos propostos, foi aplicado o método survey para obter informações dos referidos discentes, por meio de um levantamento por amostragem probabilística, e foi usado como instrumento de coleta de dados um questionário ${ }^{4}$ estruturado com questões fechadas de múltipla escolha, aplicado por e-mail e pelas redes sociais ${ }^{5}$ aos egressos e evadidos, para avaliar as percepções desses sobre o curso de graduação do qual evadiu ou concluiu 6 . 0 questionário é composto por 40 variáveis (sentenças ou assertivas). Dessas, 34 foram extraídas da literatura, resumidas e validadas por Tontini e Walter (2014), e outras seis foram propostas neste estudo. Cada variável está associada a uma dimensão específica de propensão à evasão ou à permanência do discente no curso e corresponde a uma escala de concordância do tipo Likert de cinco pontos. Cada respondente apontou um nível de concordância para cada uma das sentenças, indicando um dos pontos possíveis dessa escala, que varia de um (discordo plenamente) a cinco (concordo plenamente). A escala proposta com 40 sentenças $\left(V_{1}\right.$ a $\left.V_{40}\right)$ foi validada por cinco especialistas da área de Gestão da Educação Superior e ajustada aos objetivos da pesquisa, conforme Quadro 1.

Considerando o procedimento de estimativa da proporção populacional para população infınita (MARTINS, 2005), uma vez que não se dispõe da quantidade total de egressos e evadidos de cada curso no período analisado, o tamanho amostral foi avaliado por meio do cálculo do erro de estimativa ou margem de erro $(d)$, dado por:

$$
\text { (1) } d=Z \sqrt{ }(p q / n)
$$

\footnotetext{
4- Questionário é um instrumento de coleta de dados composto por uma série de questões ou variáveis ordenadas, aplicado sem a presença do pesquisador.

5- Para aumentar o tamanho da amostra, optou-se por também realizar a pesquisa pelas redes sociais, pois muitos e-mails e telefones constantes no Sistema de Graduação (Sisgrad) ou informados pelos discentes a Fundação para o Vestibular da UNESP (VUNESP), quando da inscrição destes no vestibular, já não estavam mais ativos.

6- Em obediência aos procedimentos éticos estabelecidos para a pesquisa científica com discentes da UNESP, foi assinado o "Termo de Compromisso para Utilização de Dados Institucionais" junto à Assessoria da Pró-Reitoria de Graduação da instituição. Nesse termo, os pesquisadores garantem 0 anonimato/confidencialidade dos sujeitos da pesquisa (discentes), bem como a divulgação dos resultados apenas em meios acadêmicos e/ou científicos, em consonância com Proc. 471389/2014-5 do Edital CNPq 22/2014.
} 
Quadro 1 - Variáveis do estudo

\begin{tabular}{|c|c|}
\hline Código da Variável & Variáveis (Sentenças) \\
\hline Y & Condição do discente (egresso ou evadido). \\
\hline$V_{1}$ & 0 curso tem qualidade. \\
\hline $\mathrm{V}_{2}$ & A matriz curricular do curso é organizada. \\
\hline $\mathrm{V}_{3}$ & A matriz curricular do curso é atualizada. \\
\hline $\mathrm{V}_{4}$ & É possível relacionar a teoria com a prática. \\
\hline$V_{5}$ & 0 sistema de avaliação é adequado. \\
\hline$V_{6}$ & Consigo aplicar o aprendizado no mercado de trabalho. \\
\hline $\mathrm{V}_{7}$ & Os docentes do curso são eficientes ao transmitir o conhecimento. \\
\hline$V_{8}$ & 0 curso atendeu às minhas necessidades acadêmicas. \\
\hline$V_{9}$ & A coordenação do curso atendeu às minhas necessidades acadêmicas. \\
\hline$V_{10}$ & A instituição atendeu às minhas necessidades acadêmicas. \\
\hline$V_{11}$ & Os docentes do curso atenderam às minhas necessidades acadêmicas. \\
\hline$V_{12}$ & A área de lazer e/ou praça de alimentação (ou equivalente) atendeu às minhas necessidades. \\
\hline$V_{13}$ & Os eventos sociais, culturais e/ou esportivos têm qualidade. \\
\hline$V_{14}$ & Os eventos acadêmicos, científicos, seminários, palestras etc. têm qualidade. \\
\hline$V_{15}$ & Os laboratórios de ensino possuem estrutura e materiais adequados. \\
\hline$V_{16}$ & A biblioteca possui estrutura e acervo adequados. \\
\hline$V_{17}$ & As salas de aulas apresentam bom estado de conservação. \\
\hline$V_{18}$ & A infraestrutura geral do campus apresenta bom estado de conservação. \\
\hline$V_{19}$ & Os banheiros são limpos e apresentam bom estado de conservação. \\
\hline $\mathrm{V}_{20}$ & Os equipamentos em sala de aula têm qualidade e apresentam condições adequadas de uso. \\
\hline$V_{21}$ & 0 curso me proporcionou aprendizado. \\
\hline $\mathrm{V}_{22}$ & 0 curso contribuiu para o meu desenvolvimento pessoal. \\
\hline $\mathrm{V}_{23}$ & Obtive boas notas ou conceitos. \\
\hline $\mathrm{V}_{24}$ & Tive a necessidade de reforço de aulas. \\
\hline $\mathrm{V}_{25}$ & 0 curso proporciona boas oportunidades profissionais. \\
\hline$V_{26}$ & 0 curso proporciona uma boa concepção profissional. \\
\hline$V_{27}$ & Tive uma boa integração socio-acadêmica com os demais discentes da turma. \\
\hline $\mathrm{V}_{28}$ & Participei das atividades extracurriculares (IC, CA, EJ, PET, Projetos de Extensão, Monitorias, etc). \\
\hline$V_{29}$ & Tive identificação com o curso escolhido. \\
\hline $\mathrm{V}_{30}$ & 0 curso foi importante para a minha qualificação profissional. \\
\hline$V_{31}$ & Fui comprometido com o curso. \\
\hline$V_{32}$ & Disponibilizei tempo (suficiente) para os estudos. \\
\hline $\mathrm{V}_{33}$ & Disponibilizei tempo (suficiente) para frequentar as aulas. \\
\hline$V_{34}$ & A renda familiar/pessoal foi suficiente para minha permanência no curso. \\
\hline$V_{35}$ & Tive boas condições de moradia e de transporte. \\
\hline$V_{36}$ & Tive necessidade de bolsa de estudo para permanecer no curso. \\
\hline$V_{37}$ & Tive estabilidade pessoal e familiar durante o curso. \\
\hline$V_{38}$ & Estive saudável durante 0 curso. \\
\hline$V_{39}$ & Tive motivação para concretizar meus objetivos. \\
\hline$V_{40}$ & Tive persistência para concretizar meus objetivos. \\
\hline
\end{tabular}

Fonte: Elaboração própria. 
onde $Z=1,96$ (abscissa da distribuição normal padrão admitindo um nível de confiança de 95\%) e $n$ é o tamanho da amostra alcançada.

A coleta dos dados foi feita entre os meses de maio e outubro de 2018. Assim, o tamanho amostral alcançado (segundo o retorno de respostas da survey durante o referido período) ficou definido em 243 discentes, sendo 77 da área de Ciências Agrárias e 166 da área de Humanidades, conforme a distribuição descrita na Tabela 1.

A Tabela 1 mostra ainda os erros $(d)$ de estimativas para a variável Y (condição do discente) obtidos a partir das amostras alcançadas, os quais são inferiores ao valor de 15\% aceito por Neres (2015), estando um pouco acima (exceto para o curso de Administração) do valor de 11\% aceito por Almeida (2018) em suas pesquisas com egressos. Assim, admitiu-se que as amostras deste trabalho são representativas das populações em estudo, uma vez que os respectivos erros de estimativa não podem ser considerados elevados.

Tabela 1 - Levantamento amostral por curso

\begin{tabular}{c|c|c|c|c|c}
\hline & Engenharia agronômica & Zootecnia & Geografia & Turismo & Administração \\
\hline Egressos $(p)$ & $80 \%$ & $84 \%$ & $79 \%$ & $73 \%$ & $81 \%$ \\
\hline Evadidos $(q)$ & $20 \%$ & $16 \%$ & $21 \%$ & $27 \%$ & $19 \%$ \\
\hline Tamanho amostral & 45 & 32 & 48 & 48 & 70 \\
\hline Erro de estimativa $(d)$ & $11,7 \%$ & $12,7 \%$ & $11,5 \%$ & $12,5 \%$ & $9,2 \%$ \\
\hline
\end{tabular}

Fonte: Dados da pesquisa, 2008.

Os dados coletados foram analisados descritivamente (tabelas e medidas descritivas) e por meio da técnica multivariada de análise de agrupamentos ou clusters, a fim de identificar agrupamentos de variáveis que influenciaram na tomada de decisão do discente de evadir ou de permanecer no curso escolhido.

Segundo Hair Jr. et al. (2009), a análise de agrupamentos ou clusters é utilizada com o objetivo de agregar elementos com base em características similares, resultando em alta homogeneidade dentro dos agrupamentos e entre agrupamentos. Neste trabalho, para a formação dos clusters, foi utilizado o procedimento hierárquico aglomerativo.

Um dos métodos mais empregados na análise de agrupamentos ou clusters é o método de Ward, que tem como base a construção de uma matriz de semelhanças ou diferenças visando a diminuir o quadrado da distância euclidiana às médias dos conglomerados. Também, baseia-se na representação desse processo por meio de um dendrograma ou gráfico em forma de árvore. Esse dendrograma mostra, no sentido da reta horizontal, a distância que cada cluster foi formado e, no sentido da reta vertical, a que distância cada objeto está em relação ao outro (HAIR JR. et al., 2009). 
Por fim, para ratificar os resultados obtidos na análise multivariada, as sentenças ou variáveis de cada cluster formado foram resumidas por meio de retas de regressão (cada uma representando um conjunto de sentenças agrupadas relativo a um curso). Assim, para identificar se, de um modo geral, existe ou não diferença significativa entre a percepção de egressos e evadidos de um determinado curso para cada conjunto de sentenças ou cluster formado, foi utilizado o teste não paramétrico de Mann-Whitney, uma vez que a condição de normalidade dos coeficientes que compõem cada uma dessas retas não é satisfeita. Então, sob a hipótese nula Ho de igualdade entre médias (ou seja, não existe diferença significativa da percepção sobre o curso), se valor $p$ for menor ou igual a $\alpha$, rejeita-se Ho.

Todas as análises foram efetuadas no software SPSS ${ }^{\circledR}$ versão 22 e considerou-se um nível de significância $\alpha$ de 5\% para os testes de hipóteses realizados.

\section{Resultados}

\section{Área de Ciências Agrárias - Cursos de Engenharia Agronômica (CE de Registro) e de Zootecnia (CE de Dracena)}

Na Tabela 2, foram destacados, de uma forma geral, os menores percentuais obtidos na pesquisa (abaixo de 50\%), indicando que menos da metade dos egressos e evadidos da área de Ciências Agrárias em estudo demonstrou concordância (parcial ou plena) com a respectiva sentença.

De acordo com a Tabela 2, observa-se, para ambos os cursos, que a maioria dos pesquisados (entre 63\% e 97\%) concordam parcial ou plenamente que o curso tinha qualidade; que a matriz curricular era organizada e atualizada e o sistema de avaliação adequado; que era possível relacionar a teoria com a prática e que os docentes foram eficientes ao transmitir o conhecimento.

No que diz respeito às necessidades acadêmicas, mais de 77\% dos discentes do curso de Engenharia Agronômica avaliam que foram atendidos, no entanto, para os discentes do curso de Zootecnia, apenas um pouco mais da metade dos discentes (entre 51\% e 70\%) considera que o curso, a instituição, a coordenação e os docentes atenderam as suas necessidades.

Com relação ao comprometimento com o curso e à disponibilidade de tempo para os estudos e para frequentar as aulas, a grande maioria dos discentes dos dois cursos (entre 71\% e 98\%) considera que teve dedicação. Nesse sentido, tanto discentes de Engenharia Agronômica como de Zootecnia concordam que obtiveram boas notas e conceitos e que não tiveram necessidade de reforço de aulas. 
Monique Matsuda dos SANTOS; Isabela Gomes Ferreira PEDROSO; Sandra Cristina de OLIVEIRA

Tabela 2 - Concordância (parcial ou plena) dos egressos e evadidos para cada sentença: cursos da área de Ciências Agrárias

\begin{tabular}{|c|c|c|c|c|c|}
\hline Variável & Engenharia Agronômica & Zootecnia & Variável & Engenharia Agronômica & Zootecnia \\
\hline$V_{1}$ & $97,1 \%$ & $96,9 \%$ & $V_{21}$ & $97,1 \%$ & $100,0 \%$ \\
\hline$V_{2}$ & $89,6 \%$ & $96,9 \%$ & $V_{22}$ & $95,7 \%$ & $73,8 \%$ \\
\hline$V_{3}$ & $79,3 \%$ & $79,1 \%$ & $V_{23}$ & $92,7 \%$ & $60,6 \%$ \\
\hline$V_{4}$ & $77,8 \%$ & $75,9 \%$ & $V_{24}$ & $43,9 \%$ & $24,1 \%$ \\
\hline$V_{5}$ & $82,3 \%$ & $62,8 \%$ & $V_{25}$ & $63,0 \%$ & $59,7 \%$ \\
\hline$V_{6}$ & $73,3 \%$ & $82,2 \%$ & $V_{26}$ & $70,3 \%$ & $49,7 \%$ \\
\hline$V_{7}$ & $86,6 \%$ & $92,2 \%$ & $V_{27}$ & $86,6 \%$ & $60,6 \%$ \\
\hline $\mathrm{V}_{8}$ & $80,7 \%$ & $69,1 \%$ & $\mathrm{~V}_{28}$ & $89,6 \%$ & $73,8 \%$ \\
\hline$V_{9}$ & $77,8 \%$ & $70,6 \%$ & $V_{29}$ & $89,6 \%$ & $49,1 \%$ \\
\hline$V_{10}$ & $82,6 \%$ & $59,1 \%$ & $V_{30}$ & $82,2 \%$ & $73,8 \%$ \\
\hline$V_{11}$ & $85,2 \%$ & $50,9 \%$ & $V_{31}$ & $98,6 \%$ & $73,8 \%$ \\
\hline$V_{12}$ & $13,2 \%$ & $65,3 \%$ & $V_{32}$ & $91,3 \%$ & $70,6 \%$ \\
\hline$V_{13}$ & $46,9 \%$ & $38,8 \%$ & $V_{33}$ & $92,7 \%$ & $75,3 \%$ \\
\hline$V_{14}$ & $73,8 \%$ & $85,3 \%$ & $V_{34}$ & $69,1 \%$ & $69,7 \%$ \\
\hline$V_{15}$ & $74,8 \%$ & $79,1 \%$ & $V_{35}$ & $70,3 \%$ & $75,9 \%$ \\
\hline$V_{16}$ & $79,3 \%$ & $89,1 \%$ & $V_{36}$ & $42,5 \%$ & $23,4 \%$ \\
\hline$V_{17}$ & $88,7 \%$ & $85,3 \%$ & $V_{37}$ & $68,9 \%$ & $28,1 \%$ \\
\hline$V_{18}$ & $79,8 \%$ & $85,3 \%$ & $V_{38}$ & $73,3 \%$ & $47,5 \%$ \\
\hline$V_{19}$ & $85,2 \%$ & $76,9 \%$ & $V_{39}$ & $82,3 \%$ & $47,5 \%$ \\
\hline$V_{20}$ & $86,6 \%$ & $100,0 \%$ & $V_{40}$ & $93,9 \%$ & $65,3 \%$ \\
\hline
\end{tabular}

Fonte: Dados da pesquisa, 2018. 
Mais de 86\% dos discentes de Engenharia Agronômica e de 60\% dos discentes de Zootecnia consideram que tiveram boa integração com os demais discentes da turma e que participaram das atividades extracurriculares oferecidas pela instituição. No entanto, a maioria dos discentes dos dois cursos (cerca de 53\% e 61\%, respectivamente) discorda de que os eventos sociais, culturais e/ou esportivos ofertados foram satisfatórios. Por outro lado, consideram que ambos os cursos proporcionaram eventos acadêmicos e científicos de qualidade.

Quanto às contribuições do curso para o aprendizado e desenvolvimento pessoal, bem como para a concepção, qualificação e oportunidades profissionais, observa-se que a maioria dos discentes de Engenharia Agronômica (entre 63\% e 97\%) concorda que o curso proporcionou tais contribuições. Além disso, mais de 60\% dos discentes de Zootecnia manifestaram a mesma opinião, exceto para a concepção profissional.

Cerca de 42\% dos discentes do curso de Engenharia Agronômica e de apenas 23\% dos discentes de Zootecnia relatam que tiveram necessidade de bolsa de estudo para permanecer no curso. Mais de 69\% dos discentes dos dois cursos concordam parcial ou plenamente que a renda familiar e/ou pessoal foi suficiente para a sua permanência no curso e que tiveram boas condições de moradia e de transporte.

Ainda que necessitassem de bolsa para permanecer no curso, a maioria (mais de 70\%) dos discentes de Engenharia Agronômica afirma que tiveram mais estabilidade pessoal, familiar e de saúde, bem como motivação e persistência para concretizar os seus objetivos, do que os discentes de Zootecnia. Nesse sentido, deduz-se que a falta de identificação dos discentes de Zootecnia com o curso escolhido (cerca de 49\%) pode ser um dos fatores que justifique tais afirmações.

Finalmente, observa-se que a infraestrutura geral do campus (laboratórios, biblioteca, banheiros, salas de aula e equipamentos) foi muito bem avaliada pelos discentes dos dois cursos, ou seja, mais de 75\% consideram que a infraestrutura tinha um bom estado de conservação. Apenas os discentes do curso de Engenharia Agronômica relatam que a área de lazer e/ou praça de alimentação (ou equivalente) não atendeu as suas necessidades (aproximadamente 87\%).

Por meio da técnica multivariada de análise de agrupamentos ou clusters, foi possível ainda identificar agrupamentos de variáveis que, quando analisadas em conjunto e relacionadas com a condição do discente (egresso ou evadido), sugerem uma influência na tomada de decisão discente de evadir ou de permanecer nos cursos da área de Ciências Agrárias.

A Figura 1 mostra os dendogramas obtidos a partir da combinação das variáveis da Tabela 1 que, segundo as respostas dos pesquisados, resultaram em 5 clusters de variáveis tanto para o curso de Engenharia Agronômica como para o curso de Zootecnia. Para tanto, foram considerados cortes (linhas vermelhas) por volta da distância 10, de forma que os clusters fossem constituídos por no mínimo três variáveis.

Utilizou-se, então, o teste não paramétrico de Mann-Whitney para verificar se, de um modo geral e de fato, a percepção dos egressos difere da percepção dos evadidos sobre esses cursos para cada agrupamento ou cluster constituído. 
Figura 1 - Dendograma dos cursos da área de Ciências Agrárias

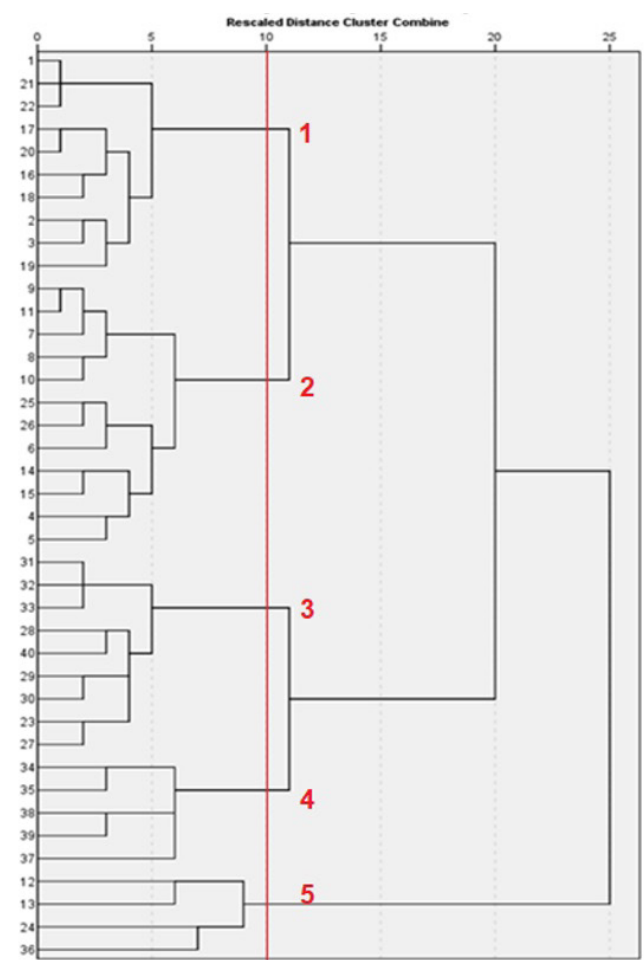

Engenharia Agronômica

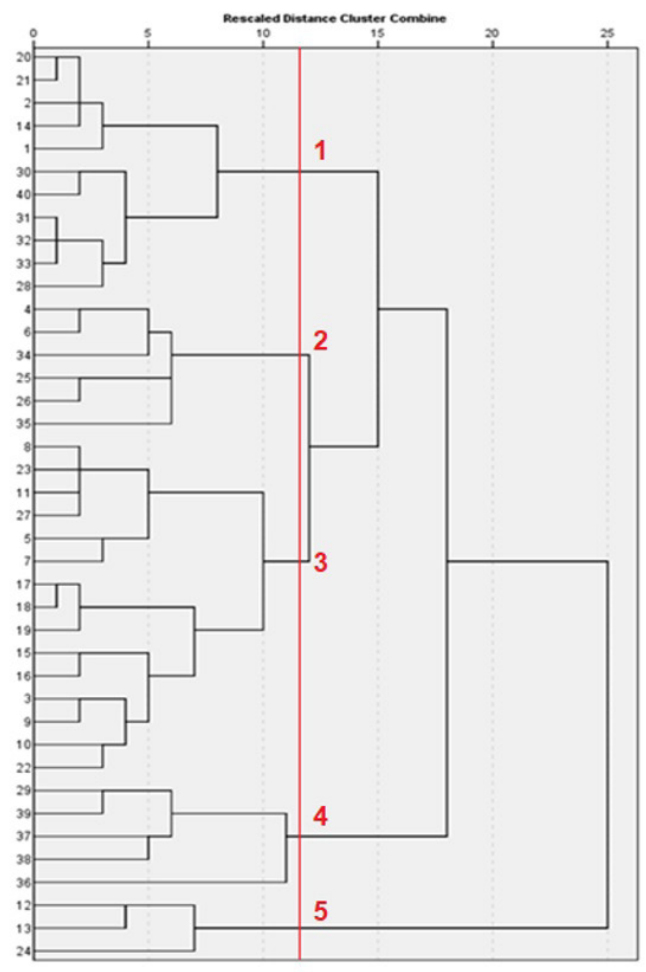

Zootecnia

Fonte: Dados da pesquisa, 2018.

A Tabela 3 mostra os resultados das probabilidades de significância (valores_p) obtidas para os testes de hipóteses feitos a partir da condição do pesquisado (egresso ou evadido) e os clusters de variáveis relativos a cada curso.

Tabela 3 - Probabilidades de significância (valores_p) obtidos nos testes de hipóteses de Mann-Whitney para os cursos da área de Ciências Agrárias

\begin{tabular}{ccc:cc}
\hline & $\vdots$ & Engenharia Agronômica & Zootecnia \\
\hline Cluster 1 & $\vdots$ & 0,944 & 0,177 \\
\hline Cluster 2 & 0,146 & 0,614 \\
\hline Cluster 3 & $\vdots$ & 0,110 & $0,050^{*}$ \\
\hline Cluster 4 & $\vdots$ & 0,378 & $0,001^{*}$ \\
\hline Cluster 5 & $\vdots$ & 0,348 & 0,614 \\
\hline
\end{tabular}

*Significativo para um nível de significância de 5\%. Fonte: Dados da pesquisa, 2018. 
De acordo com os resultados da Tabela 3, não houve diferenças significativas quanto à percepção do curso entre egressos e evadidos de Engenharia Agronômica. Apenas para o curso de Zootecnia a percepção sobre o curso relatada às variáveis que formam os clusters 3 e 4 foi significativamente diferente entre egressos e evadidos, ao nivel de 5\% de significância.

A fim de identificar o quanto essa diferença relaciona-se com a percepção dos pesquisados em cada um desses dois clusters, foi realizada a análise dos postos obtidos por meio do teste de Mann-Whitney. De acordo com a Tabela 4, observa-se que os evadidos do curso de Zootecnia apresentam postos mais baixos em ambos os clusters, mostrando que esses têm uma percepção diferenciada em relação aos egressos sobre todas ou a maioria das variáveis que compõem cada um dos clusters.

Tabela 4 - Análise dos postos obtidos pelo teste de Mann-Whitney, segundo a condição do discente do curso de Zootecnia

\begin{tabular}{|c|c|c|c|c|}
\hline & $\begin{array}{l}\text { Condição } \\
\text { do discente }\end{array}$ & $\mathrm{N}$ & Média dos postos & Soma dos postos \\
\hline \multirow{4}{*}{ Cluster 3} & Evadido & 5 & 9,20 & 46,00 \\
\hline & Egresso & 27 & 17,85 & 482,00 \\
\hline & Total & 32 & & \\
\hline & $\begin{array}{l}\text { Condição } \\
\text { do discente }\end{array}$ & N & Média dos postos & Soma dos postos \\
\hline \multirow{3}{*}{ Cluster 4} & Evadido & 5 & 4,20 & 21,00 \\
\hline & Egresso & 27 & 18,78 & 507,00 \\
\hline & Total & 32 & & \\
\hline
\end{tabular}

Fonte: Dados da pesquisa, 2018.

Ao analisar cada cluster separadamente, verifica-se que o cluster 3 é formado pelas variáveis $\mathrm{V}_{8}, \mathrm{~V}_{23}, \mathrm{~V}_{11}, \mathrm{~V}_{27}, \mathrm{~V}_{5}, \mathrm{~V}_{7}, \mathrm{~V}_{17}, \mathrm{~V}_{18}, \mathrm{~V}_{19}, \mathrm{~V}_{15}, \mathrm{~V}_{16}, \mathrm{~V}_{3}, \mathrm{~V}_{9}, \mathrm{~V}_{10}$ e $\mathrm{V}_{22}$, respectivamente, que foram agrupadas relacionando sentenças que dizem respeito especificamente ao atendimento dos docentes, da coordenação de curso e da instituição às necessidades dos discentes; à infraestrutura geral do campus; à matriz curricular, sistema de avaliação e contribuição do curso para o desenvolvimento pessoal dos discentes; à obtenção de boas notas; e, à integração socioacadêmica desses com a turma. 
Ainda que a Tabela 2 aponte resultados gerais positivos para a maioria das variáveis que compõem esse cluster, quatro delas foram avaliadas de forma negativa pelos evadidos do curso de Zootecnia, sendo que mais de 60\% desses consideram que a instituição não atendeu (de forma parcial ou plena) as suas necessidades acadêmicas, que não obtiveram boas notas, que o curso não contribuiu para o seu desenvolvimento pessoal e que não tiveram integração socioacadêmica com os demais discentes da turma. Em contrapartida, mais de 93\% dos egressos ressaltam, como pontos fortes, que os docentes do curso atenderam às suas necessidades acadêmicas, que a infraestrutura do campus apresentava bom estado de conservação e que o curso contribuiu significativamente para o seu desenvolvimento pessoal.

Já para o cluster 4, as variáveis $\mathrm{V}_{29}, \mathrm{~V}_{39}, \mathrm{~V}_{37}, \mathrm{~V}_{38}$ e $\mathrm{V}_{36}$ foram agrupadas relacionando a identificação e motivação dos discentes com o curso escolhido, bem como as condições financeiras e psicológicas desses durante o curso.

A Tabela 2 mostra resultados gerais negativos para todas as variáveis que compõem esse cluster, sendo que quatro delas foram avaliadas da mesma forma por mais de $80 \%$ dos evadidos do curso de Zootecnia, que relatam que não tiveram identificação com o curso, estabilidade pessoal e familiar, motivação e saúde para concluir o mesmo. Por outro lado, acima de 85\% dos egressos destacam, como pontos fortes, que tiveram identificação com o curso escolhido e motivação para concretizar os seus objetivos, e que estiveram saudáveis durante o curso. No que diz respeito aos demais clusters, esses mostraram-se homogêneos, em termos de percepção do curso de Zootecnia, tanto para egressos como para evadidos.

\section{Área de Humanidades - Cursos de Geografia (CE de Ourinhos), de Turismo (CE de Rosana) e de Administração (CE de Tupã)}

$\mathrm{Na}$ Tabela 5 foram destacados, de uma forma geral, os menores percentuais obtidos na pesquisa (abaixo de 50\%), evidenciando as sentenças com as quais menos da metade dos pesquisados concordou (parcial ou plenamente), para os cursos da área de Humanidades.

Conforme Tabela 5, a maioria dos discentes (entre 64\% e 96\%) tem uma percepção positiva (parcial ou plena) sobre os cursos de Geografia, Administração e Turismo, respectivamente, considerando que esses tinham qualidade e proporcionaram aprendizado. Ademais, para eles, a matriz curricular era atualizada, o sistema de avaliação foi adequado e os docentes foram eficientes ao transmitir o conhecimento, sendo cursos importantes não só para a qualificação profissional, como também para o desenvolvimento pessoal. No entanto, especificamente os discentes do curso de Turismo discordam de que foi possível relacionar a teoria com a prática e aplicar o aprendizado no mercado de trabalho. 
Tabela 5 - Concordância (parcial ou plena) dos egressos e evadidos para cada sentença: área de Humanidades

\begin{tabular}{|c|c|c|c|c|c|c|c|}
\hline Variável & Geografia & Turismo & Administração & Variável & Geografia & Turismo & Administração \\
\hline$V_{1}$ & $93,4 \%$ & $86,6 \%$ & $93,0 \%$ & $V_{21}$ & $94,7 \%$ & $91,9 \%$ & $96,1 \%$ \\
\hline$V_{2}$ & $87,2 \%$ & $70,3 \%$ & $85,8 \%$ & $\mathrm{~V}_{22}$ & $87,2 \%$ & $90,9 \%$ & $97,3 \%$ \\
\hline$V_{3}$ & $79,3 \%$ & $69,9 \%$ & $69,9 \%$ & $\mathrm{~V}_{23}$ & $80,9 \%$ & $85,6 \%$ & $88,3 \%$ \\
\hline$V_{4}$ & $80,6 \%$ & $49,8 \%$ & $68,6 \%$ & $\mathrm{~V}_{24}$ & $14,1 \%$ & $20,1 \%$ & $20,8 \%$ \\
\hline$V_{5}$ & $67,8 \%$ & $64,6 \%$ & $65,5 \%$ & $\mathrm{~V}_{25}$ & $38,8 \%$ & $43,5 \%$ & $66,9 \%$ \\
\hline$V_{6}$ & $64,1 \%$ & $53,6 \%$ & $73,7 \%$ & $V_{26}$ & $62,8 \%$ & $46,4 \%$ & $76,2 \%$ \\
\hline$V_{7}$ & $74,3 \%$ & $67,0 \%$ & $71,8 \%$ & $\mathrm{~V}_{27}$ & $88,2 \%$ & $88,0 \%$ & $91,4 \%$ \\
\hline$V_{8}$ & $61,8 \%$ & $61,2 \%$ & $77,7 \%$ & $\mathrm{~V}_{28}$ & $74,7 \%$ & $81,3 \%$ & $76,6 \%$ \\
\hline$V_{9}$ & $66,8 \%$ & $62,6 \%$ & $75,5 \%$ & $\mathrm{~V}_{29}$ & $65,8 \%$ & $70,8 \%$ & $84,2 \%$ \\
\hline$V_{10}$ & $63,2 \%$ & $66,5 \%$ & $78,3 \%$ & $V_{30}$ & $67,1 \%$ & $70,8 \%$ & $87,9 \%$ \\
\hline$V_{11}$ & $81,9 \%$ & $69,9 \%$ & $76,8 \%$ & $V_{31}$ & $82,2 \%$ & $80,3 \%$ & $90,6 \%$ \\
\hline$V_{12}$ & $1,3 \%$ & $28,7 \%$ & $30,9 \%$ & $V_{32}$ & $75,7 \%$ & $81,3 \%$ & $79,0 \%$ \\
\hline$V_{13}$ & $28,3 \%$ & $37,3 \%$ & $50,2 \%$ & $V_{33}$ & $88,5 \%$ & $94,7 \%$ & $95,3 \%$ \\
\hline $\mathrm{V}_{14}$ & $74,3 \%$ & $54,9 \%$ & $74,3 \%$ & $\mathrm{~V}_{34}$ & $67,8 \%$ & $64,1 \%$ & $78,6 \%$ \\
\hline$V_{15}$ & $75,7 \%$ & $58,9 \%$ & $74,1 \%$ & $V_{35}$ & $63,8 \%$ & $70,8 \%$ & $78,1 \%$ \\
\hline$V_{16}$ & $60,2 \%$ & $71,3 \%$ & $81,5 \%$ & $V_{36}$ & $49,0 \%$ & $48,4 \%$ & $37,4 \%$ \\
\hline$V_{17}$ & $75,7 \%$ & $91,9 \%$ & $93,2 \%$ & $V_{37}$ & $69,1 \%$ & $57,4 \%$ & $73,8 \%$ \\
\hline$V_{18}$ & $51,6 \%$ & $78,9 \%$ & $86,8 \%$ & $V_{38}$ & $89,5 \%$ & $76,0 \%$ & $81,5 \%$ \\
\hline $\mathrm{V}_{19}$ & $83,2 \%$ & $83,7 \%$ & $90,6 \%$ & $V_{39}$ & $69,4 \%$ & $54,5 \%$ & $80,1 \%$ \\
\hline$V_{20}$ & $83,2 \%$ & $93,3 \%$ & $90,2 \%$ & $V_{40}$ & $82,2 \%$ & $64,9 \%$ & $89,1 \%$ \\
\hline
\end{tabular}

Fonte: Dados da pesquisa, 2018

Quanto às necessidades acadêmicas, observa-se que entre 61\% e 82\% dos discentes dos cursos de Geografia e de Turismo consideram que o curso, a instituição, a coordenação e os docentes atenderam as suas necessidades. Já para os discentes do curso de Administração, mais de 75\% concordam que foram atendidos plena ou parcialmente.

Mais de 74\% dos discentes de tais cursos consideram que tiveram boa integração socio-acadêmica com os demais discentes da turma e que participaram das atividades extracurriculares oferecidas pela instituição. No entanto, mais da metade dos discentes discorda de que os eventos sociais, culturais e/ou esportivos ofertados foram satisfatórios. Por outro lado, consideram que a instituição proporcionou eventos acadêmicos e científicos de qualidade.

A maioria dos discentes dos três cursos (entre 75\% e 95\%) relatam que tiveram comprometimento com o curso e disponibilizaram tempo para os estudos e para frequentar as aulas. Mais de $80 \%$ consideram que obtiveram boas notas ou conceitos e não tiveram necessidade de reforço de aulas. 
No que diz respeito às contribuições para a concepção, qualificação e oportunidades profissionais, bem como para o aprendizado e desenvolvimento pessoal, mais de 67\% dos discentes de Administração concordam (plena ou parcialmente) que o curso proporcionou tais contribuições. Por outro lado, ainda que concordem com as contribuições profissionais e pessoais do curso escolhido, os discentes de Geografia e de Turismo (aproximadamente 60\%) consideram que a concepção e oportunidades profissionais não foram favorecidas.

Mais de 64\% dos discentes dos três cursos concordam parcial ou plenamente que a renda familiar e/ou pessoal foi suficiente para a sua permanência no curso e que tiveram boas condições de moradia e de transporte. Porém, quase metade dos discentes dos cursos de Geografia e de Turismo e 37\% dos discentes de Administração relatam que tiveram necessidade de bolsa de estudo para permanecer no curso.

Em relação às condições de estabilidade pessoal, familiar e de saúde, bem como à motivação e persistência para concretizar os seus objetivos durante o curso, observa-se que mais da metade dos discentes dos três cursos relatam que as tiveram, corroborando ainda com a decisão acertada (identificação) de escolha do curso.

Por fim, ressalta-se a infraestrutura geral do campus (laboratórios, biblioteca, banheiros, salas de aula e equipamentos), que foi considerada adequada ou em bom estado de conservação por mais de $60 \%$ dos discentes de tais cursos. Por outro lado, a grande maioria relata que a área de lazer e/ou praça de alimentação (ou equivalente) não atendeu as suas necessidades.

A Figura 2 mostra os dendogramas obtidos a partir da combinação das variáveis da Tabela 1 que, segundo as respostas dos pesquisados, resultaram em 4 clusters de variáveis para o curso de Geografia e para o curso de Administração, e em 5 clusters para o curso de Turismo. De forma similar a considerada para a área de Agrárias, também foram considerados aqui cortes (linhas vermelhas) por volta da distância 10, de forma que os clusters fossem constituídos por no mínimo três variáveis.

Para verificar se existe diferença entre a percepção dos egressos e evadidos desses cursos para cada agrupamento ou cluster constituído, utilizou-se mais uma vez o teste não paramétrico de Mann-Whitney, cujos resultados das probabilidades de significância (valores_p) encontram-se na Tabela 6.

Tabela 6 - Probabilidades de significância (valores p) obtidos nos testes de hipóteses de Mann-Whitney para os cursos da área de Humanidades

\begin{tabular}{ccccc|c}
\hline & & Geografia & & Turismo & Administração \\
\hline Cluster 1 & & 0,309 & & 0,981 & $0,001^{*}$ \\
\hline Cluster 2 & & 0,445 & 0,763 & $0,001^{*}$ \\
\hline Cluster 3 & $\vdots$ & 0,851 & 0,195 & 0,111 \\
\hline Cluster 4 & $\vdots$ & 0,717 & & 0,160 & 0,349 \\
\hline Cluster 5 & & - & 0,260 & - \\
\hline
\end{tabular}

*Significativo para um nível de significância de 5\%.

Fonte: Dados da pesquisa, 2018.

Conforme Tabela 6, não houve diferenças significativas quanto à percepção do curso entre egressos e evadidos de Geografia e de Turismo. Apenas para o curso de 
Administração a percepção sobre o curso relatada às variáveis que formam os clusters 1 e 2 foi significativamente diferente entre egressos e evadidos, ao nível de 5\% de significância.

Figura 2 - Dendograma dos cursos da área de Humanidades

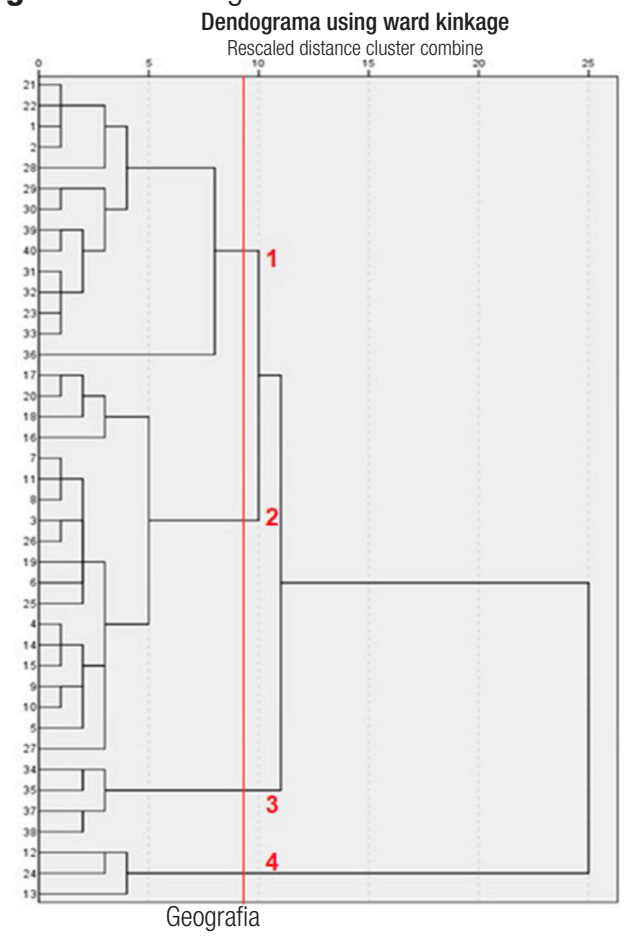

Dendograma using ward kinkage

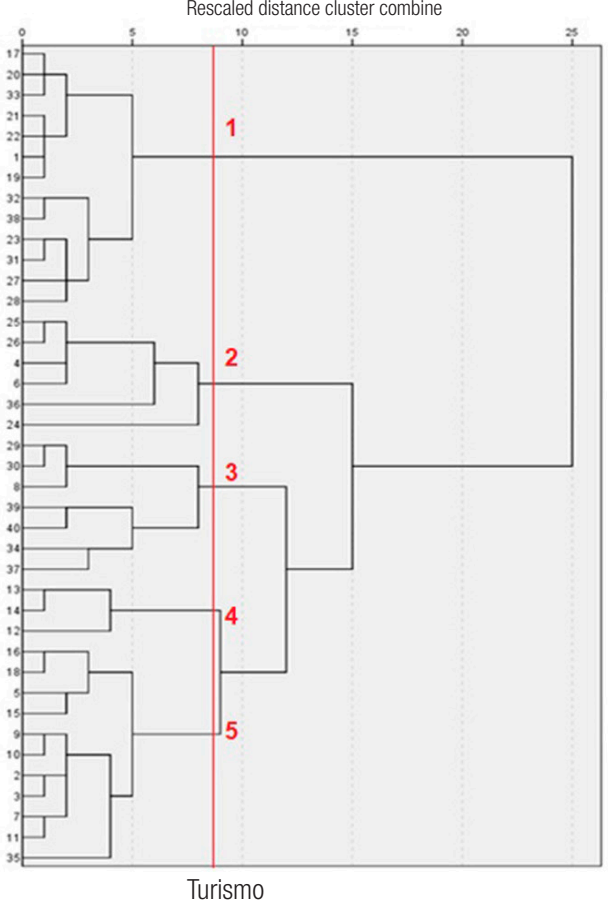

Dendograma using ward kinkage

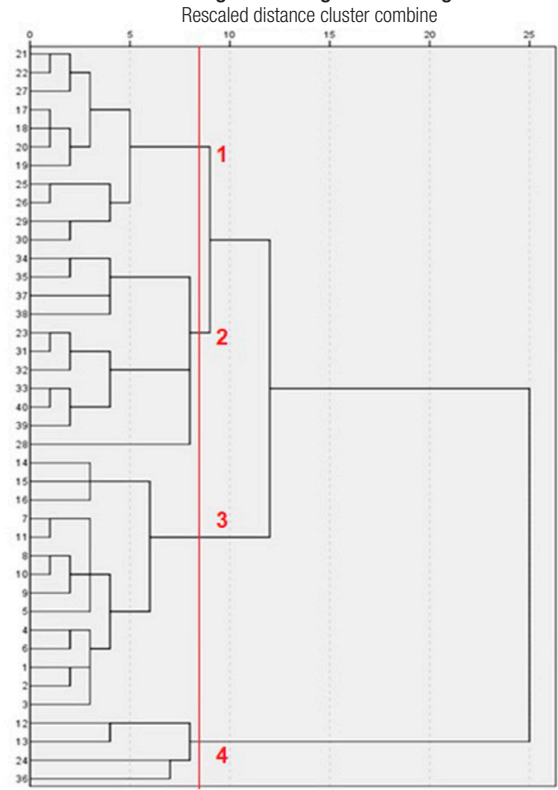

Fonte: Dados da pesquisa, 2018

Administração 
Visando a identificar o quanto essa diferença relaciona-se com a percepção dos pesquisados em cada cluster, foi realizada a análise dos postos obtidos pelo teste de Mann-Whitney, dada pela Tabela 7.

Tabela 7 - Análise dos postos obtidos pelo teste de Mann-Whitney, segundo a condição do discente do curso de Administração

\begin{tabular}{|c|c|c|c|c|}
\hline & Condição do discente & N & Média dos postos & Soma dos postos \\
\hline \multirow{4}{*}{ Cluster 1} & Evadido & 13 & 18,19 & 236,50 \\
\hline & Egresso & 57 & 39,45 & 2248,50 \\
\hline & Total & 70 & & \\
\hline & $\begin{array}{l}\text { Condição } \\
\text { do discente }\end{array}$ & N & Média dos postos & Soma dos postos \\
\hline \multirow{3}{*}{ Cluster 2} & Evadido & 13 & 18,69 & 243,00 \\
\hline & Egresso & 57 & 39,33 & 2242,00 \\
\hline & Total & 70 & & \\
\hline
\end{tabular}

Fonte: Dados da pesquisa, 2018.

Observa-se que os evadidos têm postos bem mais baixos em ambos os clusters, mostrando que tais discentes têm uma percepção diferenciada em relação aos egressos sobre todas ou a maioria das variáveis que compõem cada um desses clusters.

No cluster 1 ficaram agrupadas as variáveis $\mathrm{V}_{21}, \mathrm{~V}_{22}, \mathrm{~V}_{27}, \mathrm{~V}_{17}, \mathrm{~V}_{18}, \mathrm{~V}_{20}, \mathrm{~V}_{19}, \mathrm{~V}_{25}$, $\mathrm{V}_{26}, \mathrm{~V}_{29}$ e $\mathrm{V}_{30}$, respectivamente, que são direcionadas à infraestrutura geral do campus (salas de aula, banheiros e equipamentos), à integração socio-acadêmica com os demais discentes, à identificação com o curso escolhido, bem como à capacidade do mesmo em proporcionar aprendizado, qualificação, desenvolvimento pessoal, concepção e boas oportunidades profissionais aos discentes.

A Tabela 5 aponta resultados gerais bastante positivos (acima de 76\% de concordância) para praticamente todas as variáveis que compõem esse cluster, mas três delas podem ser destacadas por terem sido avaliadas negativamente pelos evadidos, apresentando discordância acima de 40\% quanto à identificação com o curso escolhido e à importância e oportunidades desse para a qualificação profissional. Por outro lado, mais de 95\% dos egressos relatam, como pontos fortes, uma adequada infraestrutura geral do campus e uma boa integração socio-acadêmica com os demais discentes da turma, que tiveram ainda identificação com o curso e que esse proporcionou aprendizado, desenvolvimento pessoal e qualificação profissional apropriada.

Já no cluster 2 foram agrupadas as variáveis $\mathrm{V}_{34}, \mathrm{~V}_{35}, \mathrm{~V}_{37}, \mathrm{~V}_{38}, \mathrm{~V}_{23}, \mathrm{~V}_{31}, \mathrm{~V}_{32}, \mathrm{~V}_{33}, \mathrm{~V}_{40}$, $\mathrm{V}_{39}$ e $\mathrm{V}_{28}$, que dizem respeito ao comprometimento do discente com o curso (disponibilidade de tempo para frequentar as aulas e para os estudos, obtenção de boas notas ou conceitos e participação nas atividades extracurriculares), às condições financeiras, de moradia e de transporte, às condições de estabilidade pessoal, familiar e de saúde, bem como à motivação e persistência para concretizar os seus objetivos durante o curso. 
A Tabela 5 mostra resultados gerais também positivos para todas as variáveis que compõem esse cluster, porém quatro delas foram avaliadas de forma negativa especificamente pelos evadidos do curso de Administração. Mais de 46\% desses relatam que não participaram das atividades extracurriculares proporcionadas aos discentes pela instituição e que não tiveram estabilidade pessoal e familiar durante o curso, nem motivação e persistência para concretizar os objetivos. No entanto, acima de 90\% dos egressos destacam, como pontos fortes, que foram comprometidos com o curso, disponibilizaram tempo (suficiente) para frequentar as aulas, obtiveram boas notas e tiveram motivação e persistência para concretizar os seus objetivos.

Os demais clusters mostraram-se homogêneos, com respeito à percepção do curso de Administração, tanto para egressos como para evadidos.

\section{Discussão e conclusão}

De maneira geral, pode-se destacar que egressos e evadidos dos cursos das áreas de Ciências Agrárias e de Humanidades dos CE da UNESP têm percepções positivas quanto à qualidade do curso, da matriz curricular e do sistema de avaliação, bem como quanto ao atendimento dos docentes e da coordenação, às contribuições do curso para o aprendizado e desenvolvimento pessoal, bem como às condições de infraestrutura geral dos respectivos campi (laboratórios de ensino, biblioteca, salas de aula, banheiros, equipamentos etc.). No entanto, o atendimento da área de lazer (ou equivalente) e a qualidade dos eventos, principalmente os sociais, culturais e/ou esportivos ofertados pela instituição, foram avaliados negativamente pelos discentes de praticamente todos os cursos analisados.

Os CE têm estruturas acadêmicas e administrativas mais compactas do que as das unidades universitárias da UNESP, contudo, não menos eficientes. Porém, a estrutura física desses campi foi fornecida pelo governo municipal e alguns deles ainda requerem ampliações e avanços para que os cursos, os eventos e o atendimento às necessidades dos discentes sejam ofertados com mais qualidade.

Especificamente para o curso de Engenharia Agronômica da área de Ciências Agrárias, e para os cursos de Geografia e de Turismo da área de Humanidades, não houve diferença significativa entre a percepção dos egressos e evadidos, quando do agrupamento das variáveis, que sugerisse uma influência na tomada de decisão discente de evadir ou de permanecer em tais cursos. Portanto, as informações contidas nas Tabelas 2 e 5 são suficientes para apontar pontos fortes, pontos fracos e pontos a serem melhorados, sugerindo estratégias para controle e combate à evasão. Deve-se destacar que discentes desses três cursos são os que mais necessitaram de bolsa de estudo para a permanência, bem como de reforço nas aulas e, especialmente os discentes dos cursos de Geografia e de Turismo, consideram que o curso não proporcionou boas oportunidades profissionais.

Já para o curso de Zootecnia da área de Ciências Agrárias e para o curso de Administração da área de Humanidades, observou-se que principalmente características intrínsecas relacionadas ao discente e ao seu bem-estar, tais como, falta de identificação com o curso, motivação ou persistência para concretizar os objetivos; desprovimento de saúde e de estabilidade pessoal e/ou familiar durante o curso; desinteresse em participar 
das atividades extracurriculares; e falta de integração socioacadêmica com os demais discentes da turma, são as que direta ou indiretamente interferiram na decisão discente de evadir do curso escolhido, corroborando com alguns estudos na literatura sobre o tema, já referenciados neste trabalho. Apenas os evadidos da Zootecnia consideram que a instituição não atendeu as suas necessidades.

Portanto, além das políticas de permanência estudantil, é necessária a intensificação de políticas públicas voltadas à resolução de questões pedagógicas e psicológicas que possam auxiliar os estudantes no tratamento de seus problemas pessoais e individuais, motivando-os a concluírem o curso (SOUSA; OLIVEIRA; BORGES, 2018; IMPERATORI, 2017). Litalien e Guay (2015) e Morales, Ambrose-Roman e Perez-Maldonado (2016) sugerem ainda a utilização de recursos motivacionais e de apoio psicológico por meio de tutores/conselheiros ou de docentes, além da orientação por colegas (estudantes) bemsucedidos, de forma a moldar hábitos de estudo, resultando no aumento das taxas de aprovação, na integração social e no envolvimento com a comunidade universitária.

Da mesma forma, características intrínsecas ao discente e ao seu bem-estar foram as que mais influenciaram na decisão desse de permanecer na instituição, sendo elas, comprometimento e identificação com o curso, disponibilidade de tempo (suficiente) para frequentar as aulas e, consequentemente, obter boas notas ou conceitos, além de saúde, motivação ou persistência para concretizar os objetivos. Os egressos de ambos os cursos salientam ainda a infraestrutura adequada dos campi. Nesse sentido, Tinto (1993) afırma que quanto maior a integração das características dos estudantes (capacidades e motivações acadêmicas) com as características sociais e acadêmicas da IES, menor será a chance de ocorrência da evasão.

Evidenciou-se ainda o instrumento de coleta de dados validado por especialistas da área de Gestão da Educação Superior, bem como o método proposto. Tais procedimentos poderão auxiliar as IES no desenvolvimento de novas pesquisas para diagnóstico de predisposição à evasão, baseando-se não apenas na percepção de egressos e evadidos, mas também de discentes em curso. De forma complementar, a metodologia viabiliza ainda o destaque dos pontos fortes (positivos) e dos pontos fracos (negativos) relacionados à instituição, ao curso, aos docentes e/ou aos próprios discentes, dando condições à IES de direcionar ações estratégicas e gerenciais para que os estudantes permaneçam na universidade e concluam o curso almejado.

Por fim, ressalta-se como limitação deste estudo a dificuldade em acessar egressos e evadidos para comporem a amostra. Esta situação impõe apenas que o levantamento seja feito quando da ocorrência do evento (evasão ou formação do discente), garantindo a ampliação do tamanho amostral e a confiabilidade das respostas, inclusive proporcionando que outras técnicas estatísticas de análise possam ser utilizadas.

\section{Referências}

ALMEIDA, Alexandre Nascimento de. Forças e fraquezas do curso de gestão ambiental da Universidade de Brasília. Educação e Pesquisa, São Paulo, v. 44, e166602, p. 01-16, 2018. 
ANDIFES/ABRUEM/SESu/MEC. Comissão Especial de Estudos Sobre a Evasão nas Universidades Públicas Brasileiras. Diplomação, retenção e evasão nos cursos de graduação em instituições de ensino superior públicas. Brasília, DF: MEC/SESu; Andifes; Abruem, 1997. Disponível em: http://www.andifes. org.br/ diplomacao-retencao-e-evasao-nos-cursos-de-graduacao-em-instituicoes-de-ensino-superiorpublicas. Acesso em: 9 maio 2018.

BAGGl, Christiane Aparecida; LOPES, Doraci Alves. Evasão e avaliação institucional no ensino superior: uma discussão bibliográfica. Avaliação, Sorocaba, v. 16, n. 2, p. 355-374, 2011.

BARDAGI, Marucia Patta; HUTZ, Cláudio Simon. Não havia outra saída: percepções de alunos evadidos sobre 0 abandono do curso superior. PsicoUSF, Campinas, v. 14, n. 1, p. 95-105, 2009.

CUNHA, Simone Miguez; CARRILHO, Denise Madruga. 0 processo de adaptação ao ensino superior e 0 rendimento acadêmico. Psicologia Escolar e Educacional, Campinas, v. 9, n. 2, p. 215-224, 2005.

DIOGO, Maria Fernanda et al. Percepções de coordenadores de curso superior sobre evasão, reprovações e estratégias preventivas. Avaliação, Sorocaba, v. 21, n. 1, p. 125-151, 2016.

FURTADO, Vanessa Viégas; ALVES, Tiago Wickstrom. Fatores determinantes da evasão universitária: uma análise com alunos da Unisinos. Contextus, Fortaleza, v. 10, n. 2, p.115-129, 2012.

HAIR JR, Joseph et al. Análise multivariada de dados. Porto Alegre: Bookman, 2009.

IMPERATORI, Thaís Kristosch. A trajetória da assistência estudantil na educação superior brasileira. Serviço Social \& Sociedade, São Paulo, n. 129, p. 285-303, 2017.

LITALIEN, David; GUAY, Frédéric. Dropout intentions in PhD studies: a comprehensive model based on interpersonal relationships and motivational resources. Contemporary Educational Psychology, Maryland, v. 41, p. 218-231, 2015.

MAINARDES, Emerson Wagner et al. Quem são os stakeholders de uma universidade? In: ENCONTRO DE ESTUDOS EM ESTRATÉGIA, 5., 23 a 25 de maio de 2010, Florianópolis. Anais... Florianópolis: [s. n.], 2010. p. 1.

MARTINS, Gilberto de Andrade. Estatística geral e aplicada. São Paulo: Atlas, 2005.

MASSINI-CACLIARI, Gladis et al. 0 objetivo faz o método: perspectivas para o cálculo do índice anual de evasão da Unesp. In: MANCHOPE, Elenita Conegero Pastor et al. Interiorização do ensino superior: protagonismo das universidades estaduais e municipais no desenvolvimento regional. Cascavel: Unioeste, 2018. p. 127-140.

MORALES, Erik; AMBROSE-ROMAN, Sarah; PEREZ-MALDONAD0, Rosa. Transmitting success: comprehensive peer mentoring for At-Risk students in developmental math. Innovative Higher Education, Athens, v. 41, n. 2, p. 121-135, 2016. 
NERES, Ivonaldo Vieira. Comparação do perfil e da situação entre 0 aluno evadido e 0 egresso da Faculdade UnB de Planaltina - FUP. 2015. 93 f. Dissertação (Mestrado em Políticas Públicas) Universidade de Brasília, Brasília, DF, 2015.

POLYDORO, Soely Aparecida Jorge et al. Percepção de estudantes evadidos sobre sua experiência no ensino superior. In: JOLY, Maria Cristina Rodrigues Azevedo; SANTOS, Acácia Aparecida Angeli; SISTO, Fermino Fernandes. Questões do cotidiano universitário. São Paulo: Casa do Psicólogo, 2005. p. 179-199.

SANTOS, Pricila Kohls. Abandono da educação Superior: um estudo do tipo estado do conhecimento. Revista Educação Por Escrito, Porto Alegre, v. 5, n. 2, p. 240-255, 2014.

SILVA, Glauco Peres. Análise da evasão discente no ensino superior: uma proposta de diagnóstico de seus determinantes. Avaliação, Sorocaba, v. 18, n. 2, p. 311-333, 2013.

SILVA FILHO, Roberto Leal et al. A evasão do ensino superior brasileiro. Cadernos de Pesquisa, São Paulo, v. 37, n. 132, p. 641-659, 2007.

SOUSA, António Carlos Corte-Real de; OLIVEIRA, Carlos Alberto Bragança de; BORGES, José Luís Cabral Moura. Utilização do sucesso acadêmico para prever o abandono escolar de estudantes do ensino superior: Um caso de estudo. Educação e Pesquisa, São Paulo, v. 44, e180590, p. 01-17, 2018.

TAMIN, Simon. Relevance of mental health issues in university student dropouts. Occupational Medicine, Oxford, v. 63, p. 410-414, 2013.

TEIXEIRA, José Franco; CASTR0, Luis Mota. Questões de governança e os papéis dos stakeholders no ambiente do ensino superior brasileiro. Revista Gual, Florianópolis, v. 8, n. 2, p. 237-257, 2015.

TINTO, Vincent. Dropout from higher education: a theoretical synthesis of recent research. Review of Educational Research, Washington, DC, v. 45, n.1, p. 89-125, 1975.

TINTO, Vincent. Leaving college: rethinking the causes and cures of student attrition. Chicago: University of Chicago Press, 1993.

TONTINI, Gerson; WALTER, Silvana Anita. Pode-se identificar a propensão e reduzir a evasão de alunos? Ações estratégicas e resultados táticos para instituições de ensino superior. Avaliação, Sorocaba, v. 19, n. 1, p. 89-110, 2014.

Recebido em: 27.08.2019

Revisado em: 14.05.2020

Aprovado em: 03.06.2020

Monique Matsuda dos Santos é egresso em Administração pela UNESP. Bolsista de iniciação científica PIBIC/CNPq no período de 2016 a 2018, desenvolvendo projetos sobre evasão discente no ensino superior. 
Isabela Gomes Ferreira Pedroso é graduanda em Administração pela UNESP. Bolsista de iniciação científica PIBIC/CNPq no período de 2016 a 2018, desenvolvendo projetos sobre evasão discente no ensino superior.

Sandra Cristina de Oliveira é graduada em Estatística pela UNESP, Mestre e Doutora em Ciências pela USP e Livre-docente em Estatística Aplicada pela UNESP. Professora Associada da Faculdade de Ciências e Engenharia da UNESP, desenvolvendo pesquisas relacionadas à análise estatística de dados para a solução de problemas da área de Ciências Sociais Aplicadas. 